\title{
Gender Differences in Student Performance in First Semester General Chemistry in Fifteen Week and Five Week Semester Formats
}

\author{
Kent A. Chambers* \\ Department of Chemistry \& Physics, Hardin Simmons University, Abilene, TX, United States of America \\ *Corresponding author: chambers@hsutx.edu
}

\begin{abstract}
In this study we investigated both the overall student performance and the DFW rates (the number of students receiving a grade of "D", "F", or withdrawing from a class) for both males and females in first semester general chemistry courses over a period of five years. Data was collected from a large southwestern university in the United States for all of the first semester general chemistry courses offered during this period. The data included 12 fall semester sections, 16 spring semester sections and five summer semester sections with a total sample of 5384 students. The results showed that in the traditional fifteen week semesters the female students significantly outperformed the male students in both overall class averages (ANOVA $\mathrm{p}<0.001$ ), and DFW rates (ANOVA $\mathrm{p}<0.001)$. However during the summer sessions a startling reversal occurred and the male students significantly outperformed the female students in both overall class averages (ANOVA $\mathrm{p}<0.05$ ) and DFW rate (ANOVA $\mathrm{p}<0.001)$.
\end{abstract}

Keywords: general chemistry, curriculum, learning theories, women in chemistry, chemical education research

Cite This Article: Kent A. Chambers, "Gender Differences in Student Performance in First Semester General Chemistry in Fifteen Week and Five Week Semester Formats." World Journal of Chemical Education, vol. 5, no. 4 (2017): 132-135. doi: 10.12691/wjce-5-4-3.

\section{Introduction}

There has been a significant quantity of research done concerning the learning differences between male and female students in the classroom. A small sampling of this includes: [1-7]. In addition to this, considerable work has been done to determine how to best meet the differing needs of the two genders in the classroom. These studies have typically focused on the differing learning styles between males and females, or the development of assessment tools and teaching techniques that are more gender equitable $[8,9,10]$. While this research has been essential to the continuing improvement of the educational system, there are some gaps in the research relating classroom performance and failure rate to different semester formats and gender.

Traditionally most colleges and universities operate on the two-semester system, with both the fall and spring semesters being from fifteen to sixteen weeks in length. In addition to the two long semesters, most colleges and universities offer a number of short semesters ranging from three to five weeks in length. The most common arrangement for these short semesters is five week summer sessions where students meet from two to three hours per class for four to five days per week. This study examines the effect of semester type on the DFW rate, and the overall class averages by gender, in a first semester general chemistry class over a period of five years.

\section{Methodology}

Data was collected at a large public southwestern university in the United States of America for all of the first semester general chemistry courses offered in a consecutive five year period. This included twelve sections taught in the fall semesters, sixteen sections taught in the spring semesters, and five sections taught in the summer semesters. The class was a standard general chemistry course for science and engineering majors, taught by at least fifteen different professors, using the Brown, LeMay and Bursten $9^{\text {th }}-11^{\text {th }}$ edition textbook [11] over the course of the study. A total population of 5384 students was evaluated with an overall average composition of $60.79 \%$ male students and $39.21 \%$ female students. The population breakdown by semester type is given in Table 1.

Table 1. Student Population

\begin{tabular}{|l|c|c|c|c|}
\hline & Fall & Spring & Summer & Totals \\
\hline Male Students & 1269 & 1713 & 291 & 3273 \\
\hline Female Students & 689 & 1186 & 236 & 2111 \\
\hline Total & 1958 & 2889 & 527 & 5384 \\
\hline
\end{tabular}

If we postulate that gender should not affect student performance in first semester general chemistry, then we would expect no significant differences in DFW rates or 
class averages between the male and female groups within each course section. Neither would we expect these ratios to significantly change based on whether the course was offered in the long semester or as a condensed class in the summer. This is not to say that we do not expect the absolute DFW rates or class averages to vary based on the overall quality of each individual class's population, or to change due to instructor variance. However, there should be no significant difference in class averages between males and females in each individual class, and approximately the same relative percentage of males and females should receive a "D," an "F," or withdraw from the course within each class. Thus our null hypotheses are: 1. There will be no significant difference in the relative DFW rates between males and females within each section; 2. There will be no significant difference in the relative DFW rates for males and females in the long semesters as compared to the relative DFW rates in the short summer semesters; 3. There will be no significant differences in the relative class averages between males and females within each section; and 4 . There will be no significant differences in the relative class averages for males and females in the long semesters as compared to the short summer sessions.

A Z-test for ratios was performed to compare DFW rates between males and females within each section. ANOVA was performed to compare relative DFW rates between semester types by gender. ANOVA was also performed to compare class averages between males and females within each section, and relative class averages between semester types by gender. The significance value ( $p$ value) was set at 0.05 for a $95 \%$ confidence interval.

\section{Results and Discussion}

It was determined that there was no significant difference $(p>0.05)$ in the absolute DFW rates between the normal long semesters $(\mathrm{DFW}=39.87 \%)$ and the summer semesters $(\mathrm{DFW}=38.55 \%)$. This indicates that the variance in DFW rates is relatively constant regardless of the length of the semester being studied. However, there were significant differences in the relative DFW rates between males and females depending on which semester type they were in. In $92.86 \%$ of the long semesters that were evaluated in this study, the female students had at least a slightly lower relative DFW rate than the male students. In $42.86 \%$ of the long semesters this difference was statistically significant (Z-test $\mathrm{p}<0.05)$. The average difference in relative DFW rates between males and females in the long semesters was
$7.88 \%$ (ANOVA, $\mathrm{p}<0.001$ ) with the female students having a lower DFW rate than the males (Eta-Squared $=0.566)$.

However, in the summer semesters $80 \%$ of the classes that were evaluated showed that the male students had at least a slightly lower relative DFW rate than the female students. In $60 \%$ of the summer sections the male students had a significantly lower relative DFW rate (Z-test, $\mathrm{p}<0.05)$ than the female students. The average difference in relative DFW rates between males and females in the summer semesters was $8.16 \%$ (ANOVA, $\mathrm{p}<0.001$ ) with the male students having a lower rate than the female students (Eta-Squared $=0.532)$.

When the relative DFW rates for female students were compared by semester type, it was determined that the relative DFW rates for female students was significantly (ANOVA, $\mathrm{p}<0.001$ ) higher in the summer semesters than in the long semesters, with the average difference in DFW rate by semester type being 9.23\% (Eta-Squared $=0.392$ ). It was also determined that the relative DFW rate for male students was significantly (ANOVA, $p=0.001$ ) lower in the summer semesters as compared to the long semesters, with the average difference in DFW rate by semester type being $6.80 \%$ (Eta-Squared $=0.441)$.

When the student performance was compared by class average, a similar trend to the DFW rate was discovered. After evaluation, it was determined that there was no significant difference (ANOVA, $p>0.05$ ) in the overall class averages by semester type. The overall class averages for the summers semesters was $59.67 \%$, and the overall class averages for the long semesters was $62.89 \%$. This indicates that the variance in overall class averages is effectively constant regardless of the semester type. However, there were significant differences in the relative class averages between male and female students depending on which semester type they were in.

In $96.43 \%$ of the long semesters that were evaluated in this study, the female students had at least a slightly higher class average than the male students. In $46.43 \%$ of the long semesters, this difference was statistically significant $(Z$-test, $\mathrm{p}<0.05)$. The mean difference in class averages between male and female students in the long semesters was 3.9\% (ANOVA, $\mathrm{p}<0.001$ ) with the female students having a higher class average than the male students (Eta-Squared $=0.625$ ). In $100 \%$ of the summer semesters that were evaluated in this study, the male students had at least a slightly higher class average than the female students. In $60 \%$ of the summer semesters, this difference was statistically significant (Z-test, $\mathrm{p}<0.05)$. The mean difference in class averages between male and female students in the summer semesters was $2.24 \%$ $($ ANOVA, $\mathrm{p}<0.05$, Eta-Squared $=0.925)$.

Table 2. ANOVA Results for DFW Rates by Gender and Semester Type

\begin{tabular}{|l|c|c|c|l|}
\hline Semester & $\mathrm{N}$ & P-Value & Significance & Lower DFW rate \\
\hline Long vs. Summer overall & 5384 & 0.789 & No $\mathrm{p}>0.05$ & No Significant Difference \\
\hline Male vs. Female Long Semester & 4847 & 0.000 & Yes $\mathrm{p} 0.05$ & Female by $7.88 \%$ \\
\hline Male vs. Female Summer Semester & 527 & 0.001 & Yes $\mathrm{p}<0.05$ & Male by $8.16 \%$ \\
\hline Female vs. Semester type & 2111 & 0.000 & Yes $\mathrm{p}<0.05$ & Long Semester by 9.23\% \\
\hline Male vs. Semester Type & 3273 & 0.001 & Yes $\mathrm{p}<0.05$ & Summer Semester by $6.80 \%$ \\
\hline
\end{tabular}


Table 3. ANOVA Results for Class Average by Gender and Semester Type

\begin{tabular}{|l|c|c|c|l|}
\hline Semester & N & P-Value & Significance & Higher Class Average \\
\hline Long vs. Summer overall & 5384 & 0.380 & No $\mathrm{p}>0.05$ & No Significant Difference \\
\hline Male vs. Female Long Semester & 4847 & 0.000 & Yes $\mathrm{p}<0.05$ & Female by $3.9 \%$ \\
\hline Male vs. Female Summer Semester & 527 & 0.017 & Yes $\mathrm{p}<0.05$ & Male by $2.24 \%$ \\
\hline Female vs. Semester type & 2111 & 0.000 & Yes $\mathrm{p}<0.05$ & Long Semester by $3.57 \%$ \\
\hline Male vs. Semester Type & 3273 & 0.001 & Yes $\mathrm{p}<0.05$ & Summer Semester by $2.56 \%$ \\
\hline
\end{tabular}

When the relative class averages for female students were compared by semester type, it was determined that the relative class averages for female students was significantly (ANOVA, $\mathrm{p}<0.001$ ) lower in the summer semesters than in the long semesters, with the mean difference in relative class average by semester type being $3.57 \%$ (Eta-Squared $=0.372$ ). It was also determined that the relative class average for male students was significantly (ANOVA, $\mathrm{p}=0.001$ ) higher in the summer semesters as compared to the long semesters, with the mean difference in relative class average by semester type being $2.56 \%$ (Eta-Squared $=0.437$ ).

This complete trend reversal in student performance by gender type between the long semesters and the summer semesters was quite unexpected, and was discovered during a student attrition study commissioned by the university that the original data was obtained from.

Before a discussion of the data, the author would like to acknowledge his personal opinion that taking foundational classes like general chemistry in a five week semester is sub-optimal at best. At our university we highly encourage any student that will be using general chemistry as a prerequisite course to take it in the long semester. We believe that the student will have a much better chance of retaining the prerequisite knowledge for future use in their advanced classes. While we have not scientifically evaluated this policy with a longitudinal study, student feedback over the past decade has amply supported this idea, and we feel that all students are better served with a less concentrated course presentation than can be obtained in a five week format.

The first issue that we tried to address in our analysis was that of extraneous variables. The fist variable that was evaluated was the overall populations of the classes and the groups of classes by semester type. We were not able to find any significant differences in the student populations with respect to gender distribution, class standing or area of study. The second variable we evaluated was the professors. There were no significant differences in student performance with respect to the professor's gender, and the performance reversal even occurred in the cases where the same professor taught in both the summer and the standard semester formats. Finally, we were lucky enough to get our data from a university that administers common exams throughout each semester. Thus the variances between each individual class were greatly reduced.

While the data indicates that the female students are favored in a traditional semester format, and that the male students show a lower level of performance, this was not overly concerning. First, the standard long semester has been an established best practice in the university setting for a very long time. Secondly, a 2008 report from the American Association of University Women indicated that young women were outperforming young men in both reading and math in secondary schools; which are the primary predictors for success in college [12]. However, the data that we have indicating that female students have significantly lower classroom performance and a significantly greater chance of failing to successfully complete general chemistry in a short summer semester format is very concerning.

As the author is most certainly not a cognitive or pedagogical specialist, we have not been able to establish the cause of the increased DFW rates and lower classroom performance exhibited by the female students in the summer semesters as compared to those in the long semester format. However, at this point, we have been able to establish that those differences most certainly do exist. The Eta-Squared values for the study as a whole indicates that $56.4 \%$ of the variance in DFW rate and $63.9 \%$ of the variance in class average is explained by the differences in semester type and gender.

Educational, and cognitive experts, suggest that this difference in performance may be due to the fact that the majority of female students tend to desire to master the material they are studying to a higher degree than do male students $[1,5,13,14,15]$. Obtaining this mastery could be significantly more difficult to achieve in a shortened summer semester than in a standard long semester. This is not to say that male students have no desire to master the material, but the literature indicates that they simply have a greater tendency to solve problems in an algorithmic manner without truly understanding the underlying theories behind the concepts. Studies have also indicated that male students are more willing to follow a, "Just tell me how to solve it, I don't need to understand why." method of learning under certain circumstances $[15,16,17,18]$ than do female students.

While as chemists, we do not have any answers or solutions for the gender differences that we have discovered with respect to semester format in general chemistry courses, we do believe that the information is important enough that it needs to be widely disseminated and used as the bases for future studies that may be able to explain and possibly develop solutions to these issues.

\section{Areas for Further Research}

As this study has progressed, we have become increasingly curious as to whether this pattern of gender based reversal in student performance with respect to semester type is limited only to chemistry, or is the phenomenon indeed as we suspect far more widespread. The questions that we are currently exploring are: 1. In what other disciplines does this trend of gender based student performance reversal have a similar pattern with 
the one we have discovered for general chemistry? 2. Is this pattern broad based across most disciplines or does it only effect the more vertically oriented disciplines, such as the physical sciences, mathematics, the languages and composition? We have begun the process of gathering data from multiple disciplines, and we hope to involve other institutions of higher education in our study as we obtain the resources to expand the project.

\section{Acknowledgements}

The facilities provided by Hardin Simmons University, and The cooperation of the Department of Chemistry \& Biochemistry at Texas Tech University are gratefully acknowledged. The author is also grateful for the guidance provided by Dr. Bob Blake at Glendale Arizona Community College.

\section{References}

[1] Belenky, M.; Clinchy, B.; Goldberger, R. and Tarule, J. Women's Ways of Knowing; The development of self, voice and mind, Basic Books Inc., New York, New York, 1997.

[2] Cutmore, T.; Hine, T.; Maberly, K.; Langford, N. and Hawgood, G., "Cognitive and Gender Factors Influencing Navigation in a Virtual Environment," International Journal of Human-Computer Studies, vol. 53, 223-249, Aug 2000.

[3] Honigsfeld, A. "High School Male and Female Learning-Style Similarities and Differences in Diverse Nations," Journal of Educational Research, 96(4), 195-206, March-April 2003.

[4] Lederman, M. "Gender/InEquity in Science Education: A Response," Journal of Research in Science Teaching, 40(6), 604606, 2003.

[5] National Research Council, How People Learn, National Academy Press Washington, D. C. 2000.
[6] Sormunen-Jones, C.; Chalupa, M. and Charles, T. "The Dynamics of Gender Impact on Group Achievement," Delta Pi Epsilon Journal, 42(3), 154-170, 2000.

[7] Kulturel-Konak, S.; D'Allegero M. and Dickinson, S. "Review of Gender Differences In Lerning Styles: Suggestions for STEM Education," Contemporary Issues In Education Research 4(3), 918., 2011.

[8] Brew, C. "Kolb's Learning Style Instrument: Sensitive to Gender," Educational and Psychological Measurement, 62(2), 373-390, 2002.

[9] Krockover, G. and Shepardson, D., "The Missing Links in Gender Equity Research," Journal of Research in Science Teaching, 32(3), 223-224, 1995.

[10] Tindall, T. and Hamil, B., "Gender Disparity in Science Education The Causes, Consequences, and Solution," Education, 125(2), 282-295, 2003.

[11] Brown T., LeMay H., Bursten B. and Murphy C. Chemistry the Central Science $11^{\text {th }}$ ed.; Prentice Hall, Upper Saddle River, NJ. 2009.

[12] American Association of University Women Education Foundation (AAUW), 2008 The AAUW report: Where the girls are: The facts about gender equity in education, Washington, D.C. 2008.

[13] Seegers, G. and Boekaerts, M., "Gender-Related Differences in Self-Referenced Cognitions in Relation to Mathematics," Journal for Research in Mathematics Education, vol. 27, 215-240, 1996.

[14] Brickhouse, N., "Embodying Science: A Feminist Perspective on Learning," Journal of Research in Science Teaching, 38(3) 282$295,2000$.

[15] Kolb, A.Y. and Kolb, D.A., "Learning styles and learning spaces: Enhancing the experiential learning in higher education." Academy of Management Learning \& Education, 4(2), 193-212, 2005.

[16] Gallagher, J. and Anderson, C., "Glimpse at Our History as This Century Closes," Journal of Research in Science Teaching, 36(10), 1063-1064, 1999.

[17] Baker, D., "Where is Gender and Equity in Science Education?" Journal of Research in Science Teaching, 39(8), 659-663, 2002

[18] Montello, D.; Lovelace, K.; Golledge, R. and Self, C., "SexRelated Differences and Similarities in Geographic and Environmental Spatial Abilities," Annals of the Association of American Geographers, 89(3), 515-534, 1999. 